\title{
Obstetric Thromboprophylaxis: The Swedish Guidelines
}

\author{
Pelle G. Lindqvist ${ }^{1}$ and Margareta Hellgren $^{2,3}$ \\ ${ }^{1}$ Department of Obstetrics and Gynecology, Karolinska University Hospital, 14186 Stockholm, Sweden \\ ${ }^{2}$ Department of Obstetrics and Gynecology, Sahlgrenska University Hospital Gothenburg, 41345 Gothenburg, Sweden \\ ${ }^{3}$ Department of Antenatal Care, Primary Care South Bohuslän, 43102 Molndal, Sweden \\ Correspondence should be addressed to Pelle G. Lindqvist, pelle.lindqvist@ki.se
}

Received 28 April 2011; Accepted 5 October 2011

Academic Editor: Thomas Kickler

Copyright (C 2011 P. G. Lindqvist and M. Hellgren. This is an open access article distributed under the Creative Commons Attribution License, which permits unrestricted use, distribution, and reproduction in any medium, provided the original work is properly cited.

\begin{abstract}
Obstetric thromboprophylaxis is difficult. Since 10 years Swedish obstetricians have used a combined risk estimation model and recommendations concerning to whom, at what dose, when, and for how long thromboprophylaxis is to be administrated based on a weighted risk score. In this paper we describe the background and validation of the Swedish guidelines for obstetric thromboprophylaxis in women with moderate-high risk of VTE, that is, at similar or higher risk as the antepartum risk among women with history of thrombosis. The risk score is based on major risk factors (i.e., 5-fold increased risk of thromboembolism). We present data on the efficacy of the model, the cost-effectiveness, and the lifestyle advice that is given. We believe that the Swedish guidelines for obstetric thromboprophylaxis aid clinicians in providing women at increased risk of VTE with effective and appropriate thromboprophylaxis, thus avoiding both over- and under-treatment.
\end{abstract}

\section{Introduction}

The incidence of obstetric venous thromboembolism (VTE) in the Nordic countries is estimated at 10 to 13 cases per 10000 pregnancies, half of them diagnosed during the first six weeks after birth $[1,2]$. VTE is one of the most common causes of maternal death $[3,4]$ and leads to morbidity in the form of postthrombotic syndrome in up to $50-60 \%[5,6]$. Several factors are known to increase the risk of obstetric VTE, such as personal or family history of VTE, thrombophilia, older age, high body mass index (BMI), immobilization, surgery, smoking, nulliparity, and cancer $[1,2]$.

Thromboprophylaxis during pregnancy usually consists of daily subcutaneous injections of low molecular weight heparin (LMWH), in combination with compression stockings [7-10]. There are several recommendations concerning how to identify women at high risk of VTE during pregnancy and the puerperium. Some of them divide women into lowmedium and high-risk groups $[7,8]$ and others are based on weighted risk scores $[9,10]$. Risk assessment and management of obstetric thromboprophylaxis differ in different countries.
The aim of this paper is to describe the background and validation of the Swedish guidelines for obstetric thromboprophylaxis in women with moderate-high risk of VTE. A weighted risk score for estimation of obstetric VTE risk has been used in Sweden for around 10 years. Recommendations concerning to whom, at what dose, when, and for how long thromboprophylaxis is to be administered are based on this risk score. A small number of special cases (women with antithrombin deficiency, antiphospholipid syndrome (APS) with prior VTE or prior multiple VTE, as well as those on chronic warfarin treatment) cannot be managed according to the risk score. These women are estimated to be at very high, that is, $15 \%$ or higher, risk of obstetric VTE. They are recommended "two-dose" thromboprophylaxis, which is not included in this paper. Thromboprophylaxis in relation to legal abortion, miscarriage, or ectopic pregnancy is also excluded from this paper.

\section{Methods}

The available literature from 1996 to 2000 on risk factors for obstetric VTE was reviewed. Two different risk models 
TABLE 1: Risk factors and their odds ratios (ORs) för VTE $(1,2)$.

\begin{tabular}{|c|c|c|c|}
\hline & Prevalence (\%) & Pregnancy OR & Postpartum OR \\
\hline \multicolumn{4}{|l|}{ Overweight $(\mathrm{BMI}>28)^{1}$} \\
\hline$>28 \mathrm{BMI}$ & 12.8 & 5 & 5 \\
\hline \multicolumn{4}{|c|}{ Familial thrombosis (first-degree relatives) } \\
\hline yes & 5.1 & 5 & 5 \\
\hline \multicolumn{4}{|l|}{ Age } \\
\hline$<20$ & 2.5 & 1.0 & 2.5 \\
\hline$\geq 20-<35$ & 85.2 & 1.0 & 1 \\
\hline$\geq 35$ & 12.4 & 1.0 & 1.2 \\
\hline \multicolumn{4}{|l|}{ Smoking } \\
\hline yes & 21.0 & 1.2 & 1.2 \\
\hline \multicolumn{4}{|l|}{ Parity } \\
\hline Primapara & 41.3 & 2.3 & 1.1 \\
\hline 1 birth & 35.4 & 1 & 1 \\
\hline 2 births & 15.8 & 1.3 & 1.7 \\
\hline$>2$ births & 7.3 & 2.6 & 1.8 \\
\hline \multicolumn{4}{|l|}{ Preeclampsia } \\
\hline Yes & 2.0 & & $3-5$ \\
\hline \multicolumn{4}{|l|}{ Cesarean section } \\
\hline Yes & 11.0 & & 4.9 \\
\hline \multicolumn{4}{|l|}{ FV Leiden } \\
\hline Noncarrier & 89.1 & 1 & 1 \\
\hline Heterozygotes & 10.6 & 5 & 5 \\
\hline Homozygotes & 0.3 & $25-100$ & $25-100$ \\
\hline Protein $S$ or protein $C$ deficiency & 0.1 & $5-25$ & $5-25$ \\
\hline Prothrombin gene mutation & 2.0 & 5 & 5 \\
\hline Hyperhomocysteinemia & & $2-5$ & $2-5$ \\
\hline
\end{tabular}

${ }^{1} \mathrm{BMI}>$ mean $+1 \mathrm{SD}$ in early pregnancy is regarded as overweight.

were constructed, one a weighted risk score based on major risk factors associated with a five-fold increased risk or a multiple thereof $[11,12]$, and the other an individualized computerized risk assessment using and including estimates of the absolute risk [11]. Hem-ARG, the Swedish Association of Obstetricians and Gynecologists (SFOG) reference and working group on hemostatic disturbances in obstetrics and gynecology, chosed the weighted risk score model. Swedish guidelines based on this model were published in 2004 [12], and established as a National Guideline by SFOG in 2009. The guidelines were revised in 2010-2011, resulting in the version presented here.

2.1. Risk Assessment of Obstetric VTE. To facilitate the assessment of VTE risk during pregnancy and the puerperium, a scoring system was created by adding the weight of various risk factors (Table 1) for obstetric VTE [1]. An approximately five-fold increased risk of VTE during pregnancy, shown by the odds ratio (OR) for a number of risk factors for VTE, yields one risk score point (Table 2). Three conditions, cesarean section (CS), preeclampsia, and abruptio placentae, are only considered to be risk factors during the puerperium. Since all risk factors cannot be included in an algorithm, the variable "other major risk factor" is included (Table 2) and may be used, according to the clinician's decision, in cases of malignancy, extreme obesity, and so forth. The woman's risk score is calculated as the sum of the points. Women with risk score 1 are at a five-fold increased risk, risk score 2 (two variables with 1 point or one variable with 2 points) are at a 25 -fold increased risk and risk score 3 entails a 125-fold increased risk, and so forth, compared to risk score 0 , which means no increased risk (Table 2). Women with a previous VTE or APS without VTE are given 4 risk points, regardless of other risk factors. The total risk score is the basis for determining when, how, and at what dose thromboprophylaxis should be administered (Table 3 ).

During pregnancy it is mainly women with prior VTE that reach the risk score level for thromboprophylaxis. A heterozygous carrier of Factor V Leiden (FVL) without any other risk factors has 1 risk point and would not be recommended ante- or postpartum prophylaxis. However, if she also has first-degree heredity for VTE, one more risk point is added, resulting in a risk score of 2 , leading to a recommended one week of postpartum thromboprophylaxis. If she also undergoes CS, she is given 3 risk points (FVL, heredity, and CS), resulting in a risk score of 3 , and she would be recommended six weeks of postpartum thromboprophylaxis. 
TABLE 2: Risk points, each corresponding to a five-fold increased risk, are added, yielding a risk score.

\begin{tabular}{|c|c|c|c|c|}
\hline 1 point & 2 points & 3 points & $\geq 4$ points $^{5}$ & Very high risk ${ }^{6}$ \\
\hline Heterozygote FV Leiden & Prot S deficiency & Homo FV Leiden & Prior VTE & Mechanical heart prosthesis \\
\hline Heterozygote FII mut & Prot $\mathrm{C}$ deficiency & Homo FII mut & APS without $\mathrm{VTE}^{7}$ & Chronic warfarin prophylaxis \\
\hline Overweight $^{1}$ & Immobilization $^{4}$ & & & Antithrombin deficiency \\
\hline Cesarean Section & & & & Recurrent VTE \\
\hline Heredity for $\mathrm{VTE}^{2}$ & & & & APS with VTE ${ }^{7}$ \\
\hline \multicolumn{5}{|l|}{ Age $>40$ years } \\
\hline \multicolumn{5}{|l|}{ Preeclampsia } \\
\hline \multicolumn{5}{|l|}{ Hyperhomocysteinemia $^{3}$} \\
\hline \multicolumn{5}{|l|}{ Abruptio placenta } \\
\hline \multicolumn{5}{|l|}{ Inflammatory bowel disease } \\
\hline Other major riskfactor & & & & \\
\hline
\end{tabular}

Homo: Homozygote, mut: mutation, VTE: venous thrombembolism.

APS: Antiphospholipidsyndrome, Prot: protein, FV: faktor V, FII: factor II (prothrombin).

${ }^{1}$ Overweight $=($ BMI $>28$ in early pregnancy $)$.

${ }^{2} \mathrm{VTE}$ in first-degree relative $<60$ years of age.

${ }^{3} \mathrm{Homocysteine}>8 \mu \mathrm{mol} / \mathrm{L}$ in pregnancy.

${ }^{4}$ During cast treatment for fracture or strict bed rest short-term thromboprophylaxis is recommended.

${ }^{5}$ Women with prior VTE or APS without VTE have risk score 4 independent of other risk factors.

${ }^{6}$ Women in this group are classified as "very high risk" and are not scored.

${ }^{7}$ Women with APS are recommended low dose $(75 \mathrm{mg})$ acetylsalicylic acid in addition to LMWH.

The risk score is formed by adding each point to a score between 0 and maximum 4 (for $\geq 4$ points).

TABLE 3: Management based on risk score (the sum of riskpoints in Table 1).

\begin{tabular}{ll}
\hline Risk score & \\
\hline 0 & No thromboprophylaxis \\
1 & No thromboprophylaxis \\
2 & Short-term LMWH thromboprohylaxis after delivery $(7 \text { days })^{*}$ or during immobilization \\
3 & 6 weeks of LMWH thromboprophylaxis after delivery* \\
$\geq 4$ & Antepartum thromboprophylaxis, and at least 6 weeks postpartum** \\
"Very high risk" & High-dose antepartum prophylaxis and at least 12 weeks of postpartum prophylaxis*** \\
\hline
\end{tabular}

*Initiated 4 hours after delivery.

** Women with history of VTE initiate thromboprophylaxis in early pregnancy.

${ }^{* * *}$ Thromboprophylaxis is initiated as early as possible and sometimes before pregnancy. Only women with antithrombin deficiency, chronic warfarin prophylaxis, recurrent VTE, antiphospholipidsyndrome with VTE, and those with mechanical heart prosthesis are included in this group.

The model also takes into account the variation in risk during pregnancy and the puerperium, that is, about a fivefold higher risk postpartum, at its highest during the first week after delivery $[2,13]$. This could make different durations of postpartum thromboprophylaxis possible, for example, one week (risk score 2), six weeks (risk score 3 or 4), or three months "very high risk" (Table 3). Some weak but significant risk factors are not considered in this model, such as smoking, blood group other than $\mathrm{O}$, multiple gestation, varicose veins, parity, and acute CS (as compared to elective CS). Several of these risk factors have been taken into account in another model [11] (Table 1).

\section{Recommendations}

As is evident from Table 2, LMWH thromboprophylaxis is recommended at a risk level corresponding to the antenatal risk of women with one prior VTE. This risk level can also be attained by the simultaneous existence of several risk factors in a woman with no history of VTE. The differences in ante- and postpartum risk (postpartum risk is about five-fold higher) and the quickly decreasing risk after the first postpartum week are taken into account in the scoring system. In the following, we will present "normal-dose" thromboprophylaxis, as recommended for women at moderate-high risk of VTE during pregnancy.

LMWH thromboprophylaxis is recommended as soon as pregnancy is confirmed in women with previous VTE or a risk score of at least 4 points. If thromboprophylaxis is only indicated postpartum, it is initiated about four hours after uncomplicated childbirth and no laboratory testing is required. In case of bleeding complications, an individual assessment is recommended. During pregnancy and after vaginal delivery, LMWH is usually injected in the abdominal wall. Pharmacological treatment is always combined with compression stockings, grade 1 knee socks that are used as 
TABle 4: Distribution of risk score* in a pregnant population, at delivery [17], among women with postpartum VTE, or postpartum pulmonary embolism [19].

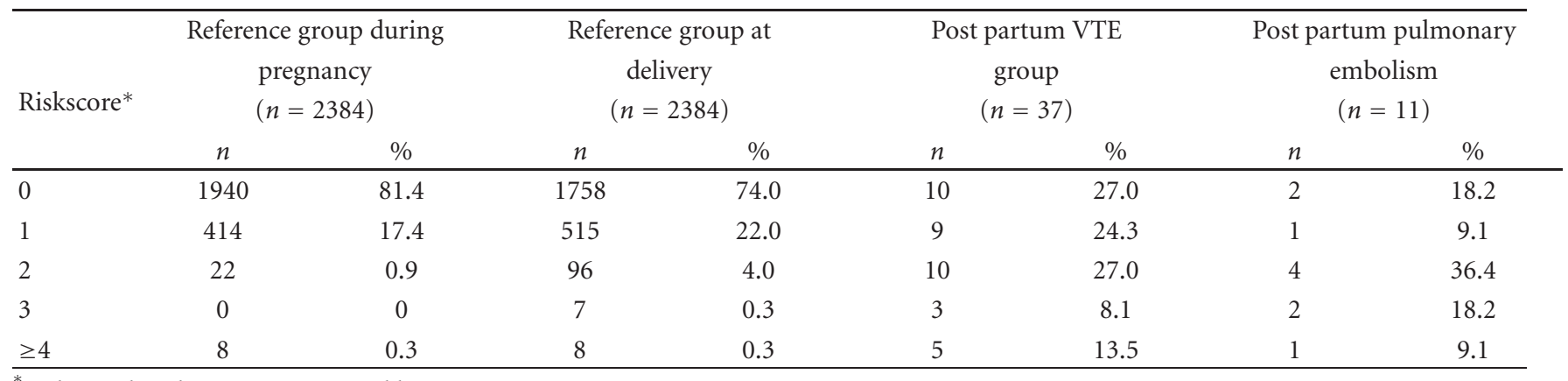

${ }^{*}$ Risk score based on anamnestic variables.

early as possible during pregnancy and continued at least 12 weeks postpartum. In the case of postthrombotic syndrome, grade 2 stockings are recommended.

3.1. "Normal Dose" Thromboprophylaxis during Pregnancy. Before the initiation of thromboprophylaxis, APTT, PT (INR), and platelet count are checked. Platelet count is repeated after two weeks of thromboprophylaxis to rule out heparin-induced thrombocytopenia (HIT). LMWH thromboprophylaxis is administered at the "normal dose" (Table 5) once daily throughout pregnancy without monitoring anticoagulant effect to women with a VTE risk score of at least 4 and body weight $\leq 90 \mathrm{~kg}$ (in early pregnancy). A higher initiation dose is recommended (Table 5) for women with a body weight exceeding $90 \mathrm{~kg}$; they should also test anti-FXa activity three hours postinjection, about 2 weeks after the initiation or dose change. An anti-FXa activity between 0.20 and $0.45 \mathrm{U} / \mathrm{mL}$ is the goal. If necessary, the dose is adjusted, reduced, or increased by half the "normal dose." If the initial anti-FXa activity is appropriate, no further verification is required, in the absence of abnormal weight gain or obstetric complications. The recommendations of different doses according to weight are based on pharmacokinetic studies and clinical experience of recurrences $[14,15]$.

In addition to the usual visits to the midwife, women with prior VTE are usually scheduled for two extra visits to an obstetrician: one at the beginning of pregnancy for planning and initiation of thromboprophylaxis and one at about 34 weeks of gestation for planning of thromboprophylaxis in relation to delivery; lifestyle information is also given (see below).

Short-term thromboprophylaxis is recommended during situations entailing temporary risk increases (e.g., fractures with casts, strict bed rest). Women with ovarian hyperstimulation syndrome (OHSS) after in vitro fertilization are given "normal-dose" thromboprophylaxis during hospitalization and for six weeks after leaving hospital.

3.2. "Normal Dose" Thromboprophylaxis during Delivery and Postpartum. On arrival at the maternity ward, APTT, PT (INR), and platelet count are assessed and the time of the last LMWH injection is recorded. Spontaneous vaginal delivery is usually planned. LMWH is discontinued during active labor and the next injection is administered about four hours after birth. Thromboprophylaxis is initiated about four hours after CS in cases with risk score $\geq 2$. The first week after CS, the injection is given in the thigh in order to avoid hematomas in the abdominal wall.

After delivery, the same dose of LMWH is given as during pregnancy and the thromboprophylaxis is continued for one (risk score 2) or six weeks (risk score 3 or 4), depending on the risk score. After complicated delivery, individualized initiation of thromboprophylaxis is mandatory. Cessation of bleeding must always take precedence before thromboprophylaxis, but it is important to start thromboprophylaxis again as soon as possible after the condition is stabilized. LMWH thromboprophylaxis is usually recommended postpartum but sometimes the women want to change to warfarin in order to avoid injections. Warfarin thromboprophylaxis makes it even more important to be vigilant for bleeding complications postpartum if abnormal bleeding occurs. The effect of warfarin may vary considerably; higher doses and more monitoring are necessary in the immediate postpartum period, compared to non-pregnant conditions [16]. If warfarin is being considered for women with protein $\mathrm{C}$ or $\mathrm{S}$ deficiency, it is initiated at a lower dose than normal and LMWH administration should continue simultaneously for at least one week.

\section{Discussion}

4.1. Thromboprophylaxis at Different Risk Levels. The risk score is a clinical aid for avoiding over- and under-treatment. The proportion of women with risk score 2 in a pregnant population is $0.9 \%$ during pregnancy and $4.0 \%$ postpartum (Table 4) [17]. The reason for this discrepancy is that CS, preeclampsia, and abruptio placentae only raise the risk of VTE postpartum (Table 2). If the risk score is the basis for clinical management, less than $5 \%$ of all women will receive LMWH thromboprophylaxis, that is, less than $0.5 \%$ of the population will receive ante- and postpartum thromboprophylaxis and $4-4.5 \%$ will only be given postpartum thromboprophylaxis.

4.2. Efficacy of LMWH Thromboprophylaxis. Without thromboprophylaxis, VTE recurs during pregnancy in about $10 \%$ 
TABLE 5: LMWH dose.

\begin{tabular}{|c|c|c|c|c|}
\hline & $\begin{array}{c}\text { Body weight* } \\
(\mathrm{Kg})\end{array}$ & $\begin{array}{l}\text { Dalteparin } \\
\text { s.c. } \mathrm{U} / 24 \mathrm{~h} \\
\end{array}$ & $\begin{array}{l}\text { Tinzaparin } \\
\text { s.c. U/24 h }\end{array}$ & $\begin{array}{c}\text { Enoxaparin } \\
\mathrm{mg} / 24 \mathrm{~h}\end{array}$ \\
\hline \multicolumn{5}{|l|}{ Risk score $=2$ to $4^{* * *}$} \\
\hline \multirow{2}{*}{ "Normal-dose" thromboprophylaxis } & $\leq 90$ & 5000 & 4500 & 40 \\
\hline & $>90$ & $7500^{* *}$ & $75 \mathrm{U} / \mathrm{kg}^{* *}$ & $60^{* *}$ \\
\hline \multicolumn{5}{|l|}{ "Very high risk" of VTE**** } \\
\hline \multirow{3}{*}{ "High-dose" thromboprophylaxis } & $<50$ & $2500 \times 2^{* *}$ & \multirow{3}{*}{$175 \mathrm{U} / \mathrm{kg}^{* *}$} & $20 \times 2 * *$ \\
\hline & $50-90$ & $5000 \times 2^{* *}$ & & $40 \times 2^{* *}$ \\
\hline & $>90$ & $7500 \times 2^{* *}$ & & $60 \times 2^{* *}$ \\
\hline
\end{tabular}

(5\% during pregnancy and 5\% postpartum) among women with a prior VTE [18]. Thromboprophylaxis according to our guidelines prevents $88 \%$ of VTE in women with one previous episode [18]. However, these women are still at a sixfold increased risk of both ante- and postpartum VTE [18]. The highest risk is during the post-treatment period, 43-100 days after delivery and termination of thromboprophylaxis [18]. During the postpartum period, there are many women without VTE history at the same risk as those with prior VTE during the antepartum period. Theoretically, the risk score should be able to reduce the number of postpartum pulmonary embolisms by two thirds [19]. Since two thirds of lethal pulmonary embolisms occur postpartum and 1/6 of maternal mortality is caused by pulmonary embolism, the risk of maternal mortality may theoretically be lowered by $1 / 12$ if the algorithm is followed [19].

Increased maternal age is an established risk factor for VTE. A five-fold increased risk is more associated with maternal age $>40$ than with the commonly quoted age of $>35$ [1]. Regarding thrombophilias, we adapted the algorithm according to practice in Sweden. Protein C and protein S deficiencies were given 2 points each. Almost all women with thrombophilia, but without history of VTE, were tested because of family history of VTE (defined as first-degree relative(s) with onset before age 60 ), yielding a risk score $2+$ $1=3$. They would usually be recommended at least six weeks of postpartum thromboprophylaxis. Homozygous FVL was given 3 risk points and these women would always be recommended at least six weeks of postpartum thromboprophylaxis.

\section{Cost-Effectiveness}

Following the guidelines has been shown to be cost-effective, especially when it comes to postpartum thromboprophylaxis for those with two and three risk points, for whom the cost of thromboprophylaxis is between $25 \%$ and $50 \%$ of the cost of thrombotic complications [19]. It is important to remember that the cost-effectiveness data is only valid if the guidelines are followed strictly.
5.1. Lifestyle Advice. Fertile women with history of VTE have an approximately $1-3 \%$ annual risk of recurrence $[18,20]$. All women with prior VTE should be given lifestyle advice. Regular exercise cuts the recurrence risk by half [21]. Exercise may be recommended in the form of walking briskly for around 30 minutes a day, in addition to normal everyday physical activity. Swimming and water aerobics are suitable right up until birth during uncomplicated pregnancy. The risk of VTE is $50 \%$ higher during the winter months than the rest of the year [22]. This may be an effect of vitamin D deficiency in a large proportion of the population, especially during winter [22]. Women with habitual sun exposure are at $30 \%$ lower risk of VTE as compared to those avoiding sun exposure [22]. Smoking increases the risk of VTE and smokers should be advised to quit [1, 23]. Women with BMI $<25$ are at a $30 \%$ lower risk of VTE than overweight (BMI 25-30) women and at three-fold lower risk than obese (BMI 30+) women [1, 23]. By maintaining normal weight, preferably through exercise, the risk of blood clots is kept low [1].

5.2. Amendments. In the revised (2011) version of the recommendations, inflammatory bowel disease was included as a risk factor [24, 25] and abruptio placentae was added as a risk factor postpartum $[2,26]$. Presently, profuse blood loss and placenta previa are being assessed as potential major risk factors. In the prior version of the guidelines, women with a provoked VTE after a temporary situation, such as orthopedic surgery, initiated their prophylaxis at 20 weeks gestation. However, after several recurrences before 20 weeks, we considered that the difference in risk between women suffering a VTE after a temporary and a permanent risk factor was not sufficient to lead to differing clinical management. All women with prior VTE are recommended thromboprophylaxis from early pregnancy, which also makes the guidelines easier to follow.

We conclude that the Swedish guidelines for obstetric thromboprophylaxis aid clinicians in providing women at increased risk of VTE with effective and appropriate thromboprophylaxis, thus avoiding both over-and under-treatment. 


\section{Conflict of Interests}

The authors have no conflict of interests.

\section{References}

[1] P. Lindqvist, B. Dahlbäck, and K. Marsál, "Thrombotic risk during pregnancy: a population study," Obstetrics and Gynecology, vol. 94, no. 4, pp. 595-599, 1999.

[2] A. F. Jacobsen, F. E. Skjeldestad, and P. M. Sandset, "Incidence and risk patterns of venous thromboembolism in pregnancy and puerperium-a register-based case-control study," American Journal of Obstetrics and Gynecology, vol. 198, no. 2, pp. e233-e237, 2008.

[3] M. Knight, "Antenatal pulmonary embolism: risk factors, management and outcomes," An International Journal of Obstetrics \& Gynaecology, vol. 115, no. 4, pp. 453-461, 2008.

[4] P. E. Marik and L. A. Plante, "Venous thromboembolic disease and pregnancy," The New England Journal of Medicine, vol. 359, no. 19, pp. 2025-2033, 2008.

[5] S. Rosfors, A. Noren, R. Hjertberg, L. Persson, K. Lillthors, and S. Torngren, "A 16-year haemodynamic follow-up of women with pregnancy-related medically treated iliofemoral deep venous thrombosis," European Journal of Vascular and Endovascular Surgery, vol. 22, no. 5, pp. 448-455, 2001.

[6] M. D. McColl, J. Ellison, I. A. Greer, R. C. Tait, and I. D. Walker, "Prevalence of the post-thrombotic syndrome in young women with previous venous thromboembolism," British Journal of Haematology, vol. 108, no. 2, pp. 272-274, 2000.

[7] C. Nelson-Piercy, P. MacCallum, and L. Mackillop, "Reducing the risk of thrombosis and embolism during pregnancy and the puerperium," in RCOG Green-Top Guideline No 37a, Royal College of Obstetricians and Gynecologists, 2009.

[8] S. M. Bates, I. A. Greer, I. Pabinger, S. Sofaer, and J. Hirsh, "Venous thromboembolism, thrombophilia, antithrombotic therapy, and pregnancy: American college of chest physicians evidence-based clinical practice guidelines," Chest, vol. 133, no. 6, pp. S844-S886, 2008.

[9] Y. Dargaud, L. Rugeri, M. C. Vergnes et al., "A risk score for the management of pregnant women with increased risk of venous thromboembolism: a multicentre prospective study," British Journal of Haematology, vol. 145, no. 6, pp. 825-835, 2009.

[10] C. Chauleur, S. Quenet, M. N. Varlet et al., "Feasibility of an easy-to-use risk score in the prevention of venous thromboembolism and placental vascular complications in pregnant women: a prospective cohort of 2736 women," Thrombosis Research, vol. 122, no. 4, pp. 478-484, 2008.

[11] P. G. Lindqvist, M. Kublikas, and B. Dahlbäck, "Individual risk assessment of thrombosis in pregnancy," Acta Obstetricia et Gynecologica Scandinavica, vol. 81, no. 5, pp. 412-416, 2002.

[12] Hem-ARG, Hemostasrubbningar Inom Obstetrik och Gynekologi, Arbets och Referensgruppen för Hemostasrubbningar, Stockholm, Sweden, 2004.

[13] H. Salonen Ros, P. Lichtenstein, R. Bellocco, G. Petersson, and S. Cnattingius, "Increased risks of circulatory diseases in late pregnancy and puerperium," Epidemiology, vol. 12, no. 4, pp. 456-460, 2001.

[14] M. Blombäck, K. Bremme, M. Hellgren, and H. Lindberg, "A pharmacokinetic study of dalteparin (Fragminß) during late pregnancy," Blood Coagulation and Fibrinolysis, vol. 9, no. 4, pp. 343-350, 1998.
[15] L. A. Norris, J. Bonnar, M. P. Smith, P. J. Steer, and G. Savidge, "Low molecular weight heparin (tinzaparin) therapy for moderate risk thromboprophylaxis during pregnancy. A pharmacokinetic study," Thrombosis and Haemostasis, vol. 92, no. 4, pp. 791-796, 2004.

[16] C. Brooks, J. M. Rutherford, J. Gould, M. M. Ramsay, and D. K. James, "Warfarin dosage in postpartum women: a case-control study," An International Journal of Obstetrics \& Gynaecology, vol. 109, no. 2, pp. 187-190, 2002.

[17] P. G. Lindqvist, P. Olofsson, and B. Dahlbäck, "Use of selective factor V Leiden screening in pregnancy to identify candidates for anticoagulants," Obstetrics and Gynecology, vol. 100, no. 2, pp. 332-336, 2002.

[18] P. G. Lindqvist, K. Bremme, and M. Hellgren, "Efficacy of obstetric thromboprophylaxis and long-term risk of recurrence of venous thromboembolism," Acta Obstetricia et Gynecologica Scandinavica, vol. 90, no. 6, pp. 648-653, 2011.

[19] P. G. Lindqvist, J. Torsson, A. Almqvist, and O. Björgell, "Postpartum thromboembolism: severe events might be preventable using a new risk score model," Vascular Health and Risk Management, vol. 4, no. 5, pp. 1081-1087, 2008.

[20] S. C. Christiansen, W. M. Lijfering, F. M. Helmerhorst, F. R. Rosendaal, and S. C. Cannegieter, "Sex difference in risk of recurrent venous thrombosis and the risk profile for a second event," Journal of Thrombosis and Haemostasis, vol. 8, no. 10, pp. 2159-2168, 2010.

[21] P. G. Lindqvist, E. Epstein, and H. Olsson, "The relationship between lifestyle factors and venous thromboembolism among women: a report from the MISS study," British Journal of Haematology, vol. 144, no. 2, pp. 234-240, 2009.

[22] P. G. Lindqvist, E. Epstein, and H. Olsson, "Does an active sun exposure habit lower the risk of venous thrombotic events? A D-lightful hypothesis," Journal of Thrombosis and Haemostasis, vol. 7, no. 4, pp. 605-610, 2009.

[23] A. F. Jacobsen, F. E. Skjeldestad, and P. M. Sandset, "Ante- and postnatal risk factors of venous thrombosis: a hospital-based case-control study," Journal of Thrombosis and Haemostasis, vol. 6, no. 6, pp. 905-912, 2008.

[24] C. N. Bernstein, J. F. Blanchard, D. S. Houston, and A. Wajda, "The incidence of deep venous thrombosis and pulmonary embolism among patients with inflammatory bowel disease: a population-based cohort study," Thrombosis and Haemostasis, vol. 85, no. 3, pp. 430-434, 2001.

[25] M. J. Grainge, J. West, and T. R. Card, "Venous thromboembolism during active disease and remission in inflammatory bowel disease: a cohort study," The Lancet, vol. 375, no. 9715, pp. 657-663, 2010.

[26] M. Prochazka, C. Happach, K. Marsal, B. Dahlbäck, and P. G. Lindqvist, "Factor V Leiden in pregnancies complicated by placental abruption," An International Journal of Obstetrics \& Gynaecology, vol. 110, no. 5, pp. 462-466, 2003. 


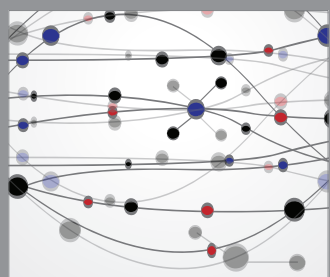

The Scientific World Journal
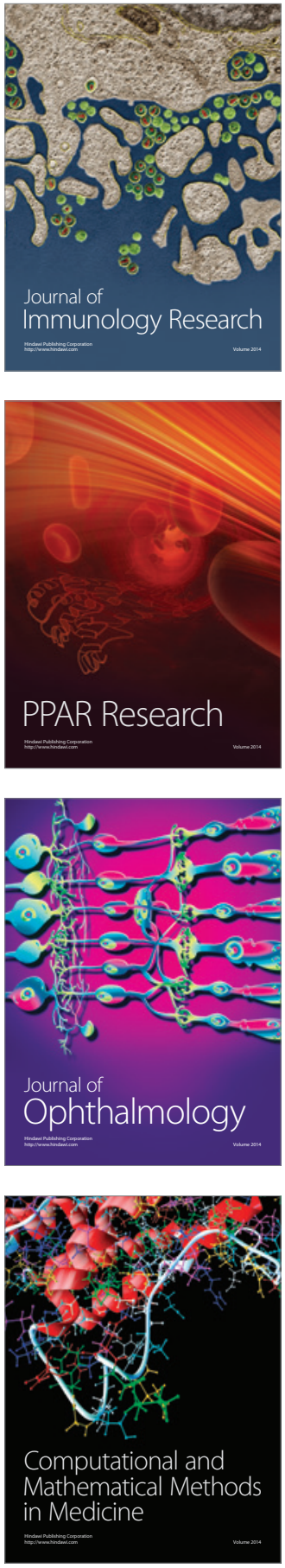

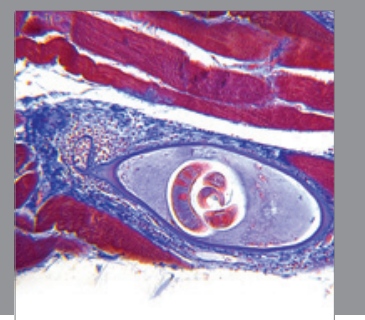

Gastroenterology

Research and Practice
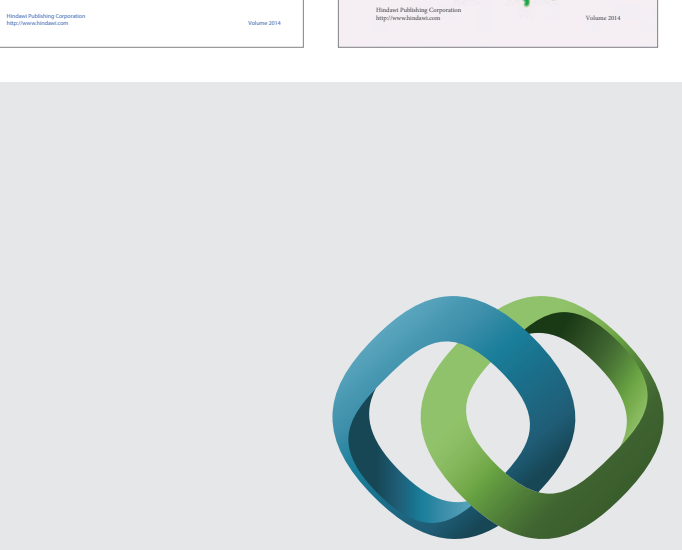

\section{Hindawi}

Submit your manuscripts at

http://www.hindawi.com
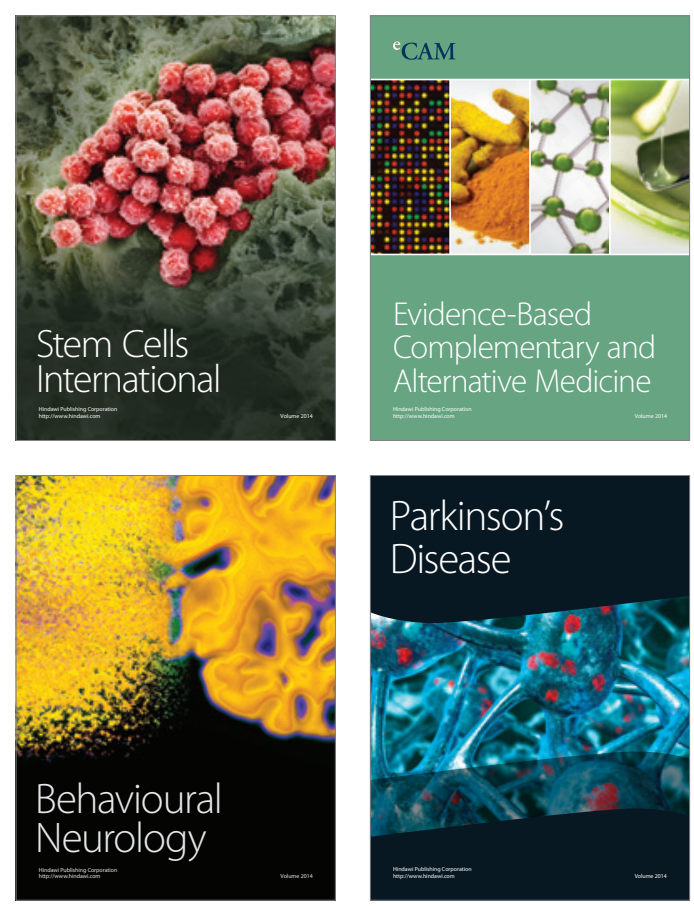

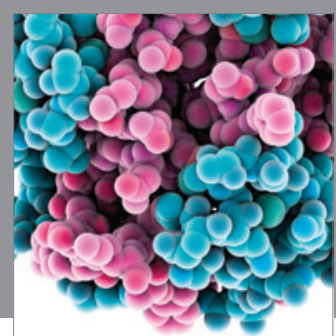

Journal of
Diabetes Research

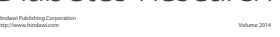

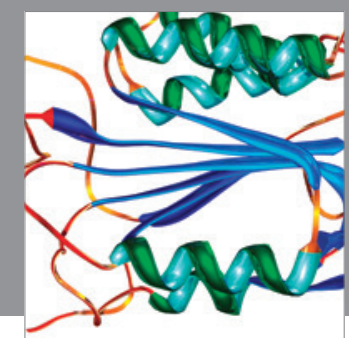

Disease Markers
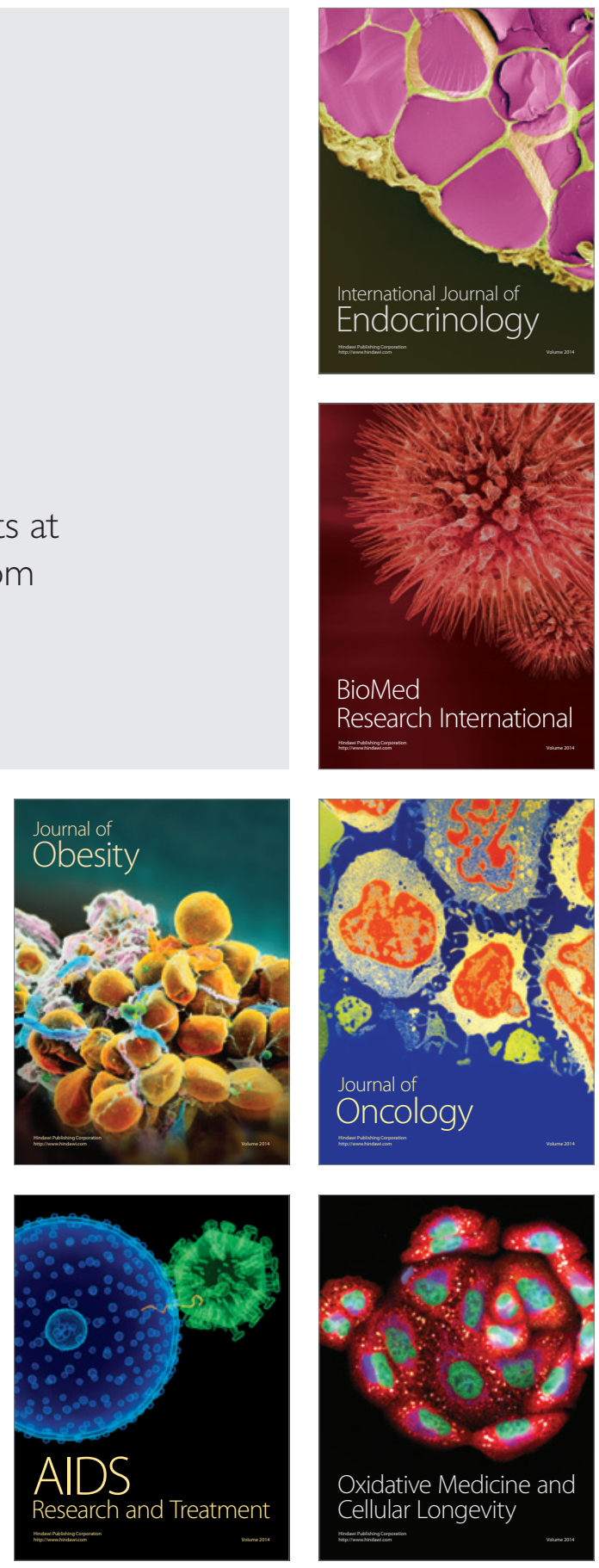